\title{
COM OU SEM “CORRIMÃO”?
}

Augusto Ponzio ${ }^{l}$

Marisol Barenco ${ }^{2}$

Tu provarás como tem gosto a sal o pão alheio e, como é duro caminho subir e descer as escadas alheias.

(Dante, Paraíso, canto XVII, vv. 58-60).

Marisol Barenco: A primeira pergunta que faço é sobre a possibilidade de existência de uma abordagem educacional - na escola e na vida - livre de correntes fechadas e guias, isto é, um tipo de "Educação sem corrimão". A seu ver, e tomando em conta seus estudos e sua pespquisa, a liberdade de toda guia é possível e mesmo desejável? Mais ainda, que consequências essa liberdade de linhas guias traria ao desenvolvimento do pensamento contemporâneo?

Augusto Ponzio: Sobre essa pergunta, a minha primeira resposta é que, como mostra o caso do "Homem selvagem de Aveyron", nenhum indivíduo humano fala e nem mesmo caminha com duas pernas e postura ereta, e não de quatro patas, sem que esteja próximo a ele alguém que lhe ensine isso. Falar e caminhar usando somente as pernas é um fato social. O homem é um animal social. Não se trata de "guia", como no caso de um passeio turístico, se trata de contexto, de ambiente, de entourage, de Umwelt social.

Marisol Barenco: Ainda tentando entender: pensar sem um corrimão é a resposta de Hannah Arendt à barbárie do genocídio hebreu e um clamor ao pensamento livre e desobediente, que assume a responsabilidade pelo mundo em uma perspectiva mais ampla, ainda que, no momento atual, as demandas sejam anti-humanizantes. É para ela um princípio de "pensar por si mesmo". Escreve Arendt: “A minha convicção é que o pensamento nasce de eventos da experiência vivida e que deve continuar a estar ligado a esses como guias que nos guiam”. Como considera essa afirmação, em relação à sua própria reflexão filosófica?

\footnotetext{
1 Augusto Ponzio, professor ordinário de Filosofia e Teoria dei linguaggi e Professor emérito, ensinou Filosofia da Linguagem e Linguística geral na Università di Bari “Aldo Moro”. Estuda e publica sobre Filosofia da Linguagem, Semiótica e Tradução, dentre outros temas, dedicando-se à filosofia de Emmanuel Levinas, Mikhail Bakhtin, Roland Barthes, dentre outros. sol.barenco@gmail.com. Orcid.org/https://0000-0001-8073-7675

${ }^{2}$ Marisol Barenco é professora associada na Faculdade de Educação da Universidade Federal Fluminense. Coordena o Grupo Atos UFF, onde realiza coletivamente estudos e pesquisas a partir da filosofia da linguagem do Círculo de Bakhtin. sol.barenco@gmail.com https://orcid.org/0000-0002-9341-0230,
} 
Augusto Ponzio: Escrevi um livro, recentemente publicado, que se intitula Con Emmanuel Levinas [Com Emmanuel Levinas] (Milano, Mimesis, 2019), e não "sobre Emmanuel Levinas", porque Levinas foi e é um "corrimão" para mim, ainda no encontro com outros textos e outros autores, como Mikhail Bakhtin Charles Sanders Peirce, etc.

Quando escreve isso que escreveu, Hannah Arendt não gostaria que assumíssemos o seu texto como nosso "corrimão"? Podemos passar sem alguns "corrimãos" dos outros, dado que há alguém que quer nos ajudar enquanto descemos escadas íngremes, incompletas, que se erguem no vazio?

A "desobediência": Pier Paolo Pasolini disse que, se perguntarmos aos jovens de hoje se consideram-se obedientes ou desobedientes, a responsta de cada um é "eu sou desobediente". A desobediência se tornou uma moda, um lugar comum, uma pose. É preciso obediência a um projeto, a um percurso, com alguém, juntos. À “desobediência" prefiro "dissidência".

Hannah Arendt disse que essa forma social, que perdura ainda (o chamo o "capitalismo cego", porque procede como um cego em um beco sem saída), prepara os jovens para serem "trabalhadores sem trabalho". O que fazer? Temos necessidade de indicações, de jalons [marcos], como a própria Hannah Arendt, Levinas, Bakhtin, Marx, Peirce, Vailati, Rossi-Landi, Morris, Sebeok, Barthes...

Um slogan de 68 era "Nem pais, nem patrões, nem mestres". Belíssimo o 68! Como uma cintilante bolha de sabão.

Marisol Barenco: Eu, ao contrário, admiro meus mestres mais que nunca. Lendo Hannah Arendt para compreender a extensão dessa sua proposta, me pareceu que, através do horror do nazismo e da perplexidade perante Eichmann e a sua posição obediente, ela queria criar essa categoria de "sem corrimão" como um clamor à liberdade de pensamento. Se há um corrimão para seguir, para ela, esse é aquele da responsabilidade pelo mundo. Gostaria que expusesse a sua visão da relação entre liberdade e responsabilidade.

Augusto Ponzio: Diante do que aconteceu no período do nazismo, as reações foram e continuam a ser diversas. A de Hannah Arendt tem as suas razões. Há seu livro, A banalidade do mal e há as leituras desse livro: “a responsabilidade pelo mundo", não sei se é isso que Hannah Arendt propõe. Contudo é uma possível interpretação. Uma responsabilidade assim genérica pode de novo tornar-se des-responsabilização: a responsabilidade pelo mundo, pelo ser. Como em Heidegger? 
A responsabilidade é pelo outro, não por um outro genérico, mas por este outro aqui, e por este aqui de novo, e de novo. É essa a "reação" de Levinas aos horrores do nazismo, maturada nos cinco anos de prisão no Stalag 1492, na região de Hannover, Stalag que recorda no seu número o ano da perseguição aos judeus na Espanha.

A responsabilidade não é uma escolha pessoal minha, uma tomada de posição minha, uma filosofia minha, uma concessão minha. É o outro, outra vez este outro aqui, a tornar-me responsável; e a lei nasce na relação de originária implicação mútua, de não-indiferença por ele, não pela situação de Homo homini lupus, que não é originária, mas é o resultado do devir histórico no qual os direitos humanos são os direitos da identidade, contrapostos aos direitos alheios, e defendidos com portas blindadas e com muros e, quando necessário, com “guerras humanitárias". É necessário reler Levinas, immer wieder, sempre de novo, hoje sobretudo, e com Levinas (é o título do meu livro citado), Mikhail Bakhtin: os meus dois principais "corrimãos".

A responsabilidade não é uma escolha pessoal, não é uma tomada de posição, e a "responsabilidade pelo mundo" é tão genérica que não significa nada. É preciso o outro que me faz passar do nominativo ao acusativo, que me pergunta, que me interroga, que me acusa, que me contesta, que quer saber se eu gosto dele, se posso ajudá-lo, se quero estar com ele, se posso dividir com ele a minha vida, se o amo. E é nessas interrogações que se decide a liberdade.

O eu não nasce livre: é o outro que o interrogando, o perguntando, o coloca na condição de responder "livremente" de um modo ou de outro. A minha liberdade vem do outro, assim como a minha responsabilidade: depende de mim depois encontrar todas as desculpas, todas as motivações, todas as justificações, para responder-lhes encontrando os álibis, alibi que a lei, geralmente leis para a vantagem da identidade e em detrimento da alteridade, lhe oferece, até poder dizer "eu fiz o meu dever", “eu obedeci à lei", "respeitei a lei”, como Hannah Arendt ouviu no famoso processo de Adolf Eichmann.

Ontem no cinema vi o filme Transatlantico Rex, de Maurizio Sciarra, o primeiro transatlântico construído na Itália, à época do fascismo, em 1932, acolhido, festejado e premiado nos Estados Unidos, e afundado no porto de Gênova, durante a segunda guerra mundial pelos ingleses, em 1944. É interessante que, quando em 1938 foram promulgadas leis raciais na Itália contra os judeus, foi feita exceção para os judeus que podiam permitir-se o luxo de viajar no Transatlantico Rex. Também sob a lei, portanto, não se assume uma responsabilidade genérica, não é lei igual para todos, mas responde caso a caso em relação aos outros sob a base da conveniência, 
do interesse do momento em relação a uma determinada identidade a ser defendida, tutelada, para proteger do medo do outro, medo que as leis mesmas criam.

Hoje está vigente a lei que permite matar por legítima defesa na Itália, promulgada pelo bem do povo, dos cidadãos, depois de ter fomentado o medo do outro, ladrão, assassino, extracomunitário, drogado, também por ter consensos, para serem votados ao governo.

A genérica "responsabilidade pelo mundo" pode fazer bem pouco diante de tudo isso. É preciso a responsabilidade pelo outro sem álibi, por parte de cada um, é preciso a substituição do medo do outro pelo medo pelo outro.

Marisol Barenco: No seu livro recentemente publicado, que agora é uma leitura "corrimão" minha, intitulado Con Emmanuel Levinas, se pode ler na página 17:

A identidade é uma abstração real, uma das principais abstrações constitutivas da realidade. Essa, como cada uma das abstrações do mesmo gênero, tem um valor ontológico. A identidade é um aspecto essencial do ser. E a violência, em todas as suas formas possíveis - incluída a guerra - é uma de suas consequências.

Nas reflexões sobre as instituições e seu próprio telos, vemos como o "Império dos sentidos do eu" prevalece como ética, como lógica e como episteme. Refletindo sobre a identidade, como considerada por Levinas, percebemos o perigo da deriva que a humanidade segue. No Brasil, como na Itália, a perspectiva política hegemonizada repete elementos fascistas que parecem estar ressuscitados, como a ignorância com que se repetem nas praças públicas, por um povo que parece sem pensamento crítico. Parece que estamos em uma sociedade de opiniões rápidas e superficiais. Quais corrimãos existem nesses pensamentos pequenos, fascistas e egoístas, sem historicidade e sem sentido? O eu e a identidade podem tornar-se um corrimão?

Augusto Ponzio: A identidade é um abrigo, uma segurança, uma justificação, em relação ao outro.

Não usarei a metáfora do corrimão para a identidade.

A identidade é um conjunto, e como tal uma abstração, mas uma abstração real, que faz parte da "realidade", do mundo assim como é, do ser, uma abstração ontológica, e por consequência da ideologia dominante.

A identidade é um lugar comum com o qual se constroem silogismos que demonstram as razões do eu em relação ao outro. Apelando-se à identidade é possível “estar certo sobre o outro" e, se protesta ou se aborrece "dar-lhe uma bela sova", também, de vez em quando, intervindo militarmente com guerras “justas e necessárias” e também com "guerras preventivas". 
Onde existe uma identidade deve haver necessariamente uma outra que é seu oposto: brancos/negros, arianos/judeus, comunitários/extra-comunitários, amigos, "os nossos"/inimigos, nós/eles, etc.

A relação eu-outro fora da identidade coloca cada eu em uma relação irreversível de responsabilidade sem álibi. É necessário então encontrar os álibis, as justificações, as argumentações para estabelecer abrigos, para levantar muros, para defender-se e para atacar.

É possível um mundo sem identidade? A identidade, como disse, é uma abstração, um conjunto, um conceito. É possível um mundo sem abstrações, sem conjuntos, sem conceitos? Absolutamente não. E então?

São necessárias abstrações que não contrastam identidades, que não favoreçam uns em relação aos outros, que não separem mas que unam, que acolham o "estranho", o "diverso", o “estrangeiro", o ëxtra-comunitário”. São necessárias leis justas, que no igualar o inigualável, isto é a singularidade de cada um, a unicidade de cada um, não favoreçam uns a respeito de "outros", não estabeleçam desigualdades e contraposições.

Somos todos "humanos". Essa grande abstração, esse grande conceito, une todos. E todavia é sempre possível, como na Fazenda dos animais de Orwell, que alguém diga que sim, é verdade, somos todos iguais, mas eu sou mais igual que os outros, ou nós somos mais iguais do que os outros. Também o "humano", malgrado a vastidão dessa identidade, desse conjunto, desse conceito, permite qualificar alguém como "inumano". Nós somos "mais humanos" que outros, e portanto podemos intervir, quando é necessário, contra eles com “guerras humanitárias”.

Nós poderemos viver juntos? É possível uma justiça justa, equitativa? São possíveis leis que garantam, defendam, favoreçam o outro e não só o idêntico? São possíveis leis que tornem o eu responsável pelo outro, sem álibi? São possíveis direitos humanos que sejam também direitos dos outros?

Humanitas não deriva da ab2019stração Homo (dessa forma seria Hominitas!), mas de humus, a terra fértil cultivada juntos, Humanitas e humilitas (humildade) têm a mesma raiz, derivam de humus.

Ninguém pode declarar-se "humilde" (eu sou humilde") sem que isso seja ao mesmo tempo negação do que se está afirmando. Com “eu sou humano" é a mesma coisa. Eu sou democrático, eu sou justo, eu sou para o bem dos outros! Bela pretensão! É o outro que o deve dizer. E a prova não é o que diz a "maioria". A prova seria que também a "minoria" o reconheça. 


\section{RESUMO}

Diálogo acontecido em março de 2019, na Universidade de Bari "Aldo Moro", na ocasião de um encontro entre os professores.

Palavras-chave: Responsabilidade; Emmanuel Lévinas; Educação; Corrimão.

\section{CON O SENZA "CORRIMANO"?}

\section{RIASSUNTO}

Dialogo che si è svolto nel marzo 2019, presso l'Università di Bari "Aldo Moro", in occasione di un incontro tra i professori.

Parole chiavi: Responsabilità; Emmanuel Lévinas; Educazione; Corrimano.

\section{¿CON O SIN BARANDILLA?}

\section{RESUMEN}

Diálogo celebrado en marzo de 2019, en la Universidad de Bari "Aldo Moro", con motivo de un encuentro entre los profesores.

Palabras clave: Responsabilidad; Emmanuel Lévinas; Educacion Barandilla

Submetido em 30 de marco de 2019 Aprovado em de agosto de 2019 